\title{
DEVELOPING LEADERSHIP CAPACITY USING VISUAL THINKING STRATEGIES
}

\section{Abstract}

In this innovative practice paper, we will illustrate how discursive practices of Visual Thinking StrategiesTM (VTS) can foster leadership development capacity of college students. We will show how VTS aligns with constructionist perspectives to post-heroic leadership grounded in discursive approaches to leadership development. This arts-based pedagogy advances leadership development through dialogue and sense-making.

\section{Introduction}

The ability to navigate complexity, uncertainty, and diversity of perspectives is crucial for emerging leaders. It may require exploring new educational practices and approaches to leadership education programs in university settings. Contemporary leadership approaches offer new lenses that support innovative practice.

Contemporary study of post-heroic leadership and the development of communicative, discursive, and relational approaches to leadership has grown significantly over the time (Alvesson \& Sveningsson, 2012; Cunliffe \& Eriksen, 2011; Drath, 2001; Raelin, 2011; Uhl-Bien \& Ospina, 2012). From a constructionist perspective, leadership is viewed as a co-constructed process in which communication is essential (Fairhurst \& Grant, 2010), emphasizing dialogue and sense-making (Drath et al., 2008; Palus \& Drath, 2001), discursive exchange and dialogic practice (Gergen \& Hersted, 2016).
Student-centered art-based pedagogical models such as Visual Thinking StrategiesTM (VTS), incorporate a set of discursive practices that foster sense-making. We (authors) have employed VTS and other visual learning approaches in interdisciplinary settings (curricular and co-curricular) with students at Kansas State University. Even though this paper focuses on practical implications of contemporary leadership approaches for college student leadership development, VTS is an inclusive engagement practice in multiple settings.

\section{Review of Related Scholarship}

Discursive Approaches to Leadership Education

Drath et al. (2008) argue that advancing leadership theory and practice calls for "a new and more integrative ontology" (p. 635). They suggest a movement away from the simplistic (and outdated) ontological commitment of an entitive "tripod" 
framework: leadership is about leaders, followers, and a common goal. Citing increasingly complex contexts for leadership that require relational and collective approaches, they reframe the tripod to focus on leadership outcomes: direction, alignment, and commitment (Drath et al., 2008). This framing shifts the focus of leadership development from, "Who are leaders and how do they interact with followers to attain shared goals?" to "How people who share work in collectives produce direction, alignment, and commitment" (2008, p. 638). This ontological shift opens up new ways of conceptualizing leadership through a relational and collective lens. Central to this perspective are processes of meaning making through dialogue (Cunliffe \& Ericksen, 2011; Palus \& Drath, 2001).

Fairhurst's (2007; 2009) discursive leadership approach illuminates the ways that language constitutes reality. Leadership actors have the ability to co-create contexts and shape social realities in and through discourse, and are in turn shaped by them (Fairhurst, 2009). A systemic constructionist approach emphasizes discursive practices, including sense-making, in investigating performance of leadership (Barge \& Fairhurst, 2008). The implication for leadership educators and scholars, then, is to both analyze and seek to develop discursive strategies used to construct meanings of leadership.

The use of reflection and dialogue to develop meaning is central to leadership education pedagogy, practice, and professional development. Examples include the use of personal journey narrative (Swain et al., 2020), storytelling (Priest \& Seemiller, 2018), literature circles (Collins et al., 2019), coaching (Kliewer \& Wanjiku Ndirangu, 2019), collaborative artistic production (Hutnick et al., 2017), and mediated dialogue (Jenkins, 2019; McGuire et al., 2015). Specially, mediated dialogue is a strategy developed by the Center for Creative Leadership that uses thought-provoking images (visual objects) to facilitate reflective, insightful conversation. The process involves "putting something in the middle" - a picture or small object - that becomes the focus of conversation (McGuire et al., 2015, p. 3). Shifting focus to the object invites multiple interpretations and perspectives that can lead to new insights and generate innovative paths forward (McGuire et al., 2015; Palus \& Drath, 2001).

These practices may be considered forms of experiential learning, a process by which the learner is actively engaged in investigating, staying curious, solving problems, and constructing meaning (Association of Experiential Education, n.d.). While the outcome of these experiences is often some form of personal learning or meaning making, we can also assume that the process of reflection itself can be an act of discursive leadership. Thus, the ways we frame, engage in, and debrief reflective dialogic activities $c$ an open up new understandings and develop discursive skills.

Visual Thinking Strategies

Initially, the research-based teaching method VTS was developed by cognitive psychologist A. Housen and museum educator $P$. Yenawine as an elementary school curriculum. Later, Yenawine and Miller examined how using the art-based pedagogical model helps the development of critical thinking and communication across disciplines, including medical schools and nursing programs (Hailey, 2014; Yenawine \& Miller, 2014).

We consider VTS as an advanced approach to mediated dialogue, as well as an experiential learning model for meaning making. VTS is grounded in dialogue due to the multilayered and interpretative nature of works of art (Hailey et al., 2015; Yenawine \& Miller, 2014). Through facilitated discussion methods, participants are encouraged to construct their own meanings and explore diverse interpretations in response to a piece of art (Chin, 2017). VTS provides an opportunity for students to develop multiple ways to read and understand situations. Building the capacity to be present 
and reflect on communication experience assists leadership (Barge \& Fairhurst, 2008).

Furthermore, skilled VTS facilitation creates an active learning environment for students' responses to be acknowledged and new meanings to be co-created and developed (Chin, 2017; Hailey, 2014). Framing the development of leadership as dialogic practice (Gergen \& Hersted, 2016), VTS fosters students' ability to transform views and ensure cooperative problem solving (Landorf, 2006; Yenawine \& Miller, 2014).

From a systemic constructionist approach and practical theory of leadership (Barge \& Fairhurst, 2008), discursive practices are essential for leadership development. As an experiential learning model, VTS promotes an innovative way to enhance the experience of dialogue and sense-making. It also fosters a learning environment for students to explore multiplicity, imagination, and uncertainty.

\section{Description of the Practice}

Our description of this leadership development practice is grounded by the assumption that higher education institutions play a unique role in developing leadership capacity (Chunoo \& Osteen, 2016) and that interdisciplinary, high-impact educational experiences can build leadership capacity and efficacy (Priest \& Clegorne, 2015). First, we will describe the use of mediated dialogue within a pathway to STEM program for undergraduate students. Then, we will describe the more formal process of VTS within interdisciplinary programming at the Marianna Kistler Beach Museum of Art at Kansas State University.

Mediated dialogue was used to deepen self-reflection of underrepresented minority students (URM) through a Pathways to STEM program at Kansas State University (see also KS-LSAMP, https://www.kstate. edu/lsamp/leadership/). Twelve community college students who participated in the eight-week summer research program in 2019 took part in a mediated dialogue activity. The summer research program was aimed to provide academic preparation to URM in STEM fields by pairing with research mentors at
K-State.

Employing visuals in facilitated discussions can foster self-reflection and ensure that engagement approaches are culturally inclusive. The Center for Creative Leadership's Visual Explorer ${ }^{\circledast}$ image cards were utilized as a tool to create a space for students to self-reflect and make sense of their research experiences on individual and collective levels. The goal of the mediated dialogue activity was to learn about students' experiences in the program and foster articulation of their thoughts and feelings.

The process utilized intentionally framed appreciative prompt questions (Cockell \& McArthur-Blair, 2012). For example, students browsed and select an image card in response to the question, "What did you learn were your greatest strengths?" Students then described their selected image, explaining how the pictures represented their responses to the question. Through a collective debrief discussion, they reflected on the experience and surfaced valuable learning, insights, or application.

As an advanced form of mediated dialogue, VTS offers an innovative way to engage participants in dialogue and sense-making. VTS sessions have become a regular part of the interdisciplinary projects conducted by the Beach Museum staff members with K-State departments such as landscape architecture, mathematics, and veterinary medicine.

VTS discussion is guided by the following protocol:

1. The facilitator presents a carefully selected image. An ideal image should contain strong narratives and understandable meanings given specific students ages and backgrounds.

2. The facilitator starts the process by asking to silently look at the image for a few moments.

3. By asking the meaning making question such as "What is going on/happening in this picture?", the facilitator encourages students to make interpretive comments. Next, the facilitator paraphrases every 
comment along with pointing the visual evidence.

4. By asking, "What do you see that makes you say that?", the facilitator encourages students to provide visual evidence in a concrete way which keeps the conversation focused on the subject.

5. By linking comments and remaining neutral, the facilitator builds the connections between students' thoughts and encourages students to make their own connections.

6. The facilitator asks, "What more can we find?" to keep encouraging the notion that there is always more to find.

7. The facilitator thanks the group for their participation (Hailey et al., 2015)

This set of discursive practices of VTS is closely related to leadership practices. VTS can result in empowering participants to communicate and recognize multiple perspectives (Hailey, 2014). Asking an open-ended question such as "What is going on in this picture?" for intentionally selected images with elements that could be interpreted variously offers an opportunity to develop an ability to tolerate ambiguity and uncertainty (Hailey, 2014; Yenawine \& Miller, 2014). In this regard, by engaging in VTS sessions, students can develop skills for dealing with complex information, navigating adaptive challenges (Heifetz, 1994), and divergent set of meanings and interpretations (Barge \& Fairhurst, 2008).

By paraphrasing and accepting each comment neutrally, the facilitator creates a respectful environment for everyone to be heard and acknowledged, which promotes inclusive communication and leadership. By linking comments, including both agreements and disagreements, the facilitator fosters meaning making, dialogue, and collaborative learning. These outcomes align with discursive practices of leadership and leadership-aspractice (Barge, 2012; Raelin, 2011). Participants are encouraged to notice new facets of the situation and reconsider their views through the question, "What more can we find?" (Hailey, 2014). Shared insights lead to mutual transformation that can signify relational leadership (Uhl-Bien, 2006). Consequently, students can advance their leadership capacity by engaging in VTS sessions over time.

\section{Discussion of Outcomes/Results}

The integration of this tool within our student programs and leadership courses is ongoing, and there is a need to develop formal evaluation of learning outcomes and impact. However, our observational data suggests that participation in mediated dialogue and VTS sessions assists students with:

- advancing observation skills and active listening

- getting comfortable with uncertainty and ambiguity

- developing skills for navigating complex situations

- engaging in collaborative learning and problem-solving

- recognizing multiple perspectives and a diverse set of interpretation

Moreover, participation in VTS sessions helps students to develop evidence-based reasoning and critical thinking over time (Hailey, 2014).

\section{Reflections of the Practitioner}

Reflecting on V TS observation and facilitation experiences in an interdisciplinary setting, we would like to point out that contextually grounded selection of pieces of art is the essential step for a successful VTS discussion. Multilayered meanings of works of art can create an inclusive learning environment and allow authentically connect with one another. It also helps facilitators and participants meet each other where they are at as responses and reactions tend to be linked to participants' past experiences and identities. Also, maintaining non-judgmental 
paraphrasing and linking of every comment is crucial for deep meaning making and dialogue and, ultimately, the mutual transformation.

\section{Recommendations}

There are multiple opportunities to explore the future application of VTS, including the advancement of discursive practices using art-based pedagogy for capacity building and leadership development programs. We believe that VTS promotes interdisciplinary, consistent path forward in leadership education. It has an enormous potential for educational practices in university settings.

VTS offers a developmental approach consistent with evolving theory and practice. There is an opportunity for further examination of postheroic leadership through individual and collective sense-making and dialogue in multiple settings. VTS has excellent potential for advancing ways to foster inclusive civic engagement. VTS can also be used as an inquiry method/engaged research.

\section{Acknowledgement}

We wish to acknowledge the help provided by our colleagues Linda Duke, Kim Richards, and Kathrine Walker Schlageck from the Marianna Kistler Beach Museum of Art at Kansas State University. Their insight, expertise, and VTS training greatly assisted with work on this manuscript. 


\section{References}

Association for Experiential Education. (n.d.) What is experiential education? https://www.aee.org/what-is-ee

Alvesson, M. \& Sveningsson, S. (2012) Un- and Re-packing leadership: Context, relations, constructions and politics. In M. Uhl-Bien \& S. M. Ospina (Eds.), Advancing relational leadership: A dialogue among perspectives (pp. 203-225). Information Age Publishing.

Barge, J., \& Fairhurst, G. (2008). Living Leadership: A Systemic Constructionist Approach. Leadership, 4(3), 227-251.

Chin, C. (2017). Comparing, contrasting and synergizing visual thinking strategies (VTS) and aesthetic education strategies in practice. International Journal of Education through Art, 13(1), 61-75.

Chunoo, V., \& Osteen, L. (2016). Purpose, mission, and context: The call for educating future leaders. New Directions for Higher Education, 174, 9-20. 10.1002/he.20185

Cockell, J., \& McArthur-Blair, J. (2012). Appreciative inquiry in higher education a transformative force (1st ed., Jossey-Bass higher and adult education series). San Francisco: Jossey-Bass.

Collins, D. P., Bruce, J., \& McKee, K. (2019). Teaching transformative leadership for social justice: Using literature circles to enhance learning and create deeper meaning. Journal of Leadership Education, 18(3), 158-166. 10.12806/V18/I3/A1

Cunliffe, A., \& Eriksen, M. (2011). Relational leadership. Human Relations, 64(11), 1425-1449.

Drath, W. H. (2001). The deep blue sea: Rethinking the source of Leadership. Jossey-Bass.

Drath, W. H., McCauley, C. D., Palus, C. J., Van Velsor, E., O'Connor, P. M. G., \& McGuire, J. B. (2008). Direction, alignment, commitment: Toward a more integrative ontology of leadership. Leadership Quarterly, 19(6), 635-653.

Fairhurst, G. (2007). Discursive leadership: In conversation with leadership psychology. Sage.

Fairhurst, G. T. (2009). Considering context in discursive leadership research. Human Relations, 62(11), 1607-1633.

Fairhurst, G. T., \& Grant, D. (2010). The social construction of leadership: A sailing guide. Management Communication Quarterly, 24(2), 171-210.

Gergen, K. J., \& Hersted, L. (2016). Developing leadership as dialogic practice. In J. A. Raelin Ed.), Leadershipas-practice: Theory and application (pp. 178-197). Routledge.

Hailey, D. (2014). Visual thinking, art, and university teaching across disciplines. About Campus, 19(4), 9-16

Hailey, D., Miller, A., \& Yenawine, P. (2015). Understanding visual literacy: The visual thinking strategies approach. In Essentials of Teaching and Integrating Visual and Media Literacy: Visualizing Learning (pp. 49-73). Springer International Publishing.

Heifetz, R. (1994). Leadership without easy answers. Harvard University Press. 


\section{References}

Hutnick, C., Galloway, K., Joyner, D., Owen, J. E., \& Constantine, S.S. (2017). Creative leadership as social action and transformation: A case study. Journal of Leadership Studies, 11, 52-58. 10.1002/jls.21513

Jenkins, D. (2019). Why don't you just meet me in the middle? Using metaphor cards to enhance and facilitate mediated dialogue in leadership education. Proceedings from the 29th Annual Association of Leadership Educators Conference (pp. 167-171). https:// www.leadershipeducators.org/resources/Documents/Annual\%20Conference\%20Proceedings\% 2012-11-19.pdf

Kliewer, B. W., \& Wanjiku Ndirangu, B. (2019). Advancing reciprocity in cross-cultural leadership coaching. Journal of Leadership Education, 18(4), 178-187. 10.12806/V18/14/A4

Landorf, H. (2006). What's going on in this picture? Visual thinking strategies and adult learning. New Horizons in Adult Education \& Human Resource Development, 20(4), 28-32.

McGuire, J. B., Palus, C. J., \& Quinn, L. (2015). Mediated dialogue: See your way through change. [White Paper] Change leadership perspectives: The arts of transformation. Center for Creative Leadership. https://www.ccl.org/articles/white-papers/mediated-dialogue-see-your-way-through-change/

Palus, C. J., \& Drath, W. H. (2001). Putting something in the middle: An approach to dialogue. Reflections, $3(2), 28-39$.

Priest, K. L., \& Clegorne, N. A. (2015). Connecting to experience: High-impact practices for leadership development. In J. E. Owen (Ed.). New Directions for Student Leadership: No. 145. Innovative Learning for leadership development (pp. 71-83). Jossey-Bass.

Priest, K. L., \& Seemiller, C. (2018). Past experiences, present beliefs, future practices: Using narratives to re(present) leadership educator identity. Journal of Leadership Education, 17(1), 93-113. 10.12806/V17/11/ R3

Raelin, J. (2011). From leadership-as-practice to leaderful practice. Leadership, 7(2), 195-211.

Swain, J. E., Bond, A. L., \& Smith, D. R. (2020). Looking back in order to move ahead as a leader: A personal journey line narrative exercise. Journal of Leadership Education, 19(1), 37-43.10.12806/V19/11/A4

Uhl-Bien, M. \& Ospina, S. M. (Eds.) (2012). Advancing relational leadership: A dialogue among perspectives. Information Age Publishing.

Yenawine, P., \& Miller, A. (2014). Visual thinking, images, and learning in college. About Campus, 19(4), 2-8. 